\title{
OS DIREITOS FUNDAMENTAIS DO TRABALHADOR COMO LIMITE AO PODER DO EMPREGADOR
}

\section{THE FUNDAMENTAL RIGHTS OF THE WORKER AS TO LIMIT THE POWER OF THE EMPLOYER.}

\author{
Suzidarly Ribeiro Teixeira Fernandes ${ }^{1}$
}

\begin{abstract}
RESUMO
O presente estudo pretende lançar luzes sobre o tema "direitos fundamentais do trabalhador como limite ao poder do empregador". Cuida-se de tema que tem instigado juristas de diversos países e que ostenta caráter atemporal. Após analisar - conceito e alcance da própria noção de direitos fundamentais, sua evolução histórica, eficácia e a tendência universalizadora da aplicação desses direitos, voltase a atenção para os direitos fundamentais na relação de trabalho e os poderes do empregador. Evidencia-se a necessidade de reconhecer que o respeito aos direitos fundamentais na relação de trabalho é condição sine qua non à dignidade da pessoa trabalhadora e à própria valorização do trabalho. Partindo desse pressuposto, será objeto de análise a limitação imposta aos poderes do empregador pelos direitos fundamentais do trabalhador, limitação esta que se verifica em todas as etapas da relação laboral: na fase pré-contratual, no período de vigência do contrato laboral e mesmo após a extinção do pacto de trabalho. Sem olvidar a legitimidade do exercício dos poderes do empregador, considerado por alguns também como exercício de um direito fundamental, assinala-se a prioridade dada aos direitos que assegurem a dignidade humana do trabalhador em casos de conflito entre tais poderes e os direitos fundamentais do trabalhador. Entendendo como inevitável a ocorrência de colisão, faz-se uma reflexão sobre as formas de harmonizar os interesses em conflito. Utilizou-se, como metodologia, a pesquisa bibliográfica.
\end{abstract}

PALAVRAS-CHAVE: Direitos Fundamentais. Relação de Trabalho. Poderes do Empregador. Conflito de Interesses. Harmonização.

\begin{abstract}
The present study aims to shed some light on "the fundamental rights of the worker as to limit the power of the employer." This subject has prompted jurists all over the world and boasts timeless character. After analyzing the concept and the scope of the notion about fundamental rights, their historical development, efficacy and universalizing tendency of the implementation of these rights, turns attention to

\footnotetext{
${ }^{1}$ Juíza do Trabalho do TRT da 10 ${ }^{\underline{a}}$ Região, especialista em Direito do Trabalho e Direito Processual do Trabalho.
} 
fundamental rights in the employment relationship and the power of the employer. This research evidences the necessity of recognizing the fundamental rights respect in the employment relationship as a sine qua non condition to the worker dignity and the appreciation of the employees work. Based on this presupposition, the object of analysis is the limitation on the powers of the employer for the fundamental rights of workers this limitation existing in all levels of the employment relationship: precontractual period, the length of the labor contract and even after the end of the labor agreement. Also mentioning the legitimacy of the employer powers, considered by some as an exercise of a fundamental right, it is noted the priority given to the rights that ensure human dignity of employees in case of conflict between these powers and the fundamental rights of workers. Understanding how inevitable a collision is, it's a reflection of ways to harmonize the conflicting interests. It was used as methodology the bibliographical research.

KEYWORDS: Fundamental Rights. Employment Relationship. Power of Employers. Conflict of Interests. Harmonization.

\section{CONSIDERAÇÕES INICIAIS}

No presente estudo, após analisar o conceito e alcance da própria noção de direitos fundamentais, sua evolução histórica, eficácia e a tendência universalizadora da aplicação desses direitos, volta-se a atenção para os direitos fundamentais na relação de trabalho e os poderes do empregador. Ganham destaque os princípios da igualdade e da dignidade da pessoa humana como fundamentos dos direitos fundamentais e do próprio Estado Democrático de Direito.

Ao longo desse artigo, que é fundado em pesquisa bibliográfica, evidencia-se a necessidade de reconhecer que o respeito aos direitos fundamentais na relação de trabalho é condição sine qua non à dignidade da pessoa trabalhadora e à própria valorização do trabalho. Partindo desse pressuposto, será objeto de análise a limitação imposta aos poderes do empregador pelos direitos fundamentais do trabalhador, limitação esta que se verifica em todas as etapas da relação laboral: na fase pré-contratual, no período de vigência do contrato laboral e mesmo após a extinção do pacto de trabalho.

Sem olvidar a legitimidade do exercício dos poderes do empregador, considerado por alguns também como exercício de um direito fundamental, assinalase a prioridade dada aos direitos que assegurem a dignidade humana do trabalhador em casos de conflito entre tais poderes e os direitos fundamentais do trabalhador. 
Entendendo como inevitável a ocorrência de colisão, faz-se uma reflexão sobre as formas de harmonizar os interesses em conflito. Destaca-se a imprescindibilidade dessa harmonização, para a qual se exige um esforço contínuo e conjunto de todos os atores da relação de trabalho, preservando-se o princípio geral do direito de que 'a ninguém se deve lesar' (neminem laedere), mas, sobretudo, prestigiando-se os direitos fundamentais.

\section{OS DIREITOS FUNDAMENTAIS}

Antes de se analisar a imbricação existente entre os direitos fundamentais na relação de trabalho e os poderes do empregador, faz-se necessário delimitar a própria noção de direitos fundamentais.

Para o professor Maurício Godinho Delgado (2013), "Direitos Fundamentais são prerrogativas ou vantagens jurídicas estruturantes da existência, afirmação e projeção da pessoa humana e de sua vida em sociedade".

Encontram-se, na doutrina e jurisprudência, distintos termos, utilizados como sinônimos de 'direitos fundamentais', tais como: Direitos Humanos, Direitos da Pessoa Humana, Direitos Humanos Fundamentais, entre outros.

José Cláudio Monteiro de Brito Filho (2013) informa que o jurista Almir de Oliveira, na obra Curso de Direitos Humanos, opta pela expressão 'Direitos Humanos Fundamentais', por ser a pessoa humana o pressuposto dos direitos humanos, sendo os direitos humanos fundamentais os que, inerentes à pessoa, não Ihe podem ser negados, devendo ser reconhecidos, respeitados e protegidos.

Brito Filho (2013) ainda ressalta que mencionada denominação é observada também por Alexandre de Moraes e Manoel Gonçalves Ferreira Filho, sendo que este utiliza como sinônimas as expressões 'Direitos Humanos' e 'Direitos Fundamentais'.

É certo, porém, que respeitáveis autores distinguem 'Direitos Humanos' e 'Direitos Fundamentais', como faz Willis Santiago Guerra Filho ${ }^{2}$ (1997), que assevera:

De um ponto de vista histórico, ou seja, na dimensão empírica, os direitos fundamentais são, originalmente, direitos humanos. Contudo, estabelecendo um corte epistemológico, para estudar sincronicamente os direitos fundamentais, devemos distingui-los, enquanto manifestações

${ }^{2}$ Citado por José Cláudio Monteiro de Brito Filho (2013). 
positivas do direito, com aptidão para a produção de efeitos no plano jurídico, dos chamados direitos humanos, enquanto pautas ético-políticas, situadas em uma dimensão suprapositiva, deonticamente diversa daquela em que se situam as normas jurídicas especialmente aquelas de direito interno" (BRITO FILHO, 2013, p. 26/27).

Na mesma direção, Fábio Konder Comparato, citado por José Cláudio Monteiro de Brito Filho (2013, p. 27), evidencia que a doutrina jurídica contemporânea classifica os direitos fundamentais como sendo direitos humanos "consagrados pelo Estado como regras constitucionais escritas".

Ingo Wolfgang Sarlet (1998) ressalta que, conquanto haja uma crescente positivação interna dos direitos humanos, essa expressão não pode ser entendida como sinônima de Direitos Fundamentais, porquanto diferem quanto à efetividade.

Assim, segundo o referido autor, os direitos fundamentais (insertos no direito interno) possuem, ao menos em regra, (ou, pelo menos, estão em melhores condições para isto) maior grau de efetivação, particularmente em face da existência de instâncias - especialmente as judiciárias - dotadas do poder de fazer respeitar e realizar estes direitos ((idem).

Os direitos humanos, como garantias previstas em diversos instrumentos de Direito Internacional Público, não raras vezes são desprovidos de fatores instrumentais que Ihe possibilitem aplicação simplificada e acessível a todas as pessoas.

É importante evidenciar, ainda com fundamento nas lições de Sarlet (1998), que o rol dos direitos fundamentais não está limitado aos dos direitos humanos.

Feita a necessária distinção entre Direitos Humanos e Direitos Fundamentais, cumpre assinalar que a amplitude da relevância e discussão dos Direitos Fundamentais, que se espraiam por toda a Ciência Jurídica, é incompatível com a pequenez da presente reflexão, que se restringe aos Direitos Fundamentais na relação de trabalho.

Sobre o tema, Godinho Delgado leciona que:

O conceito de direito fundamental do trabalho, contudo, volta a estar presente, sem dúvida, na Constituição por meio dos princípios, valores e fundamentos das ordens econômica e social, que sejam afirmativos da dignidade da pessoa humana e da valorização do trabalho. É o que se passa, por exemplo, com o artigo 170 ('Princípios Gerais da Atividade Econômica'), com o art. 193 ('Disposição Geral' relativa à 'Ordem Social'), com os arts. 196 e 197, além do art. 200, II e VIII (todos tratando da saúde), também com o art. 205 (tratando da educação), além dos arts. 225 e 227 que tratam das garantias a crianças e adolescentes no país (em acréscimos 
à regra protetora já lançada no art. 7ํ, XXXIII, da mesma Constituição). Os direitos fundamentais do trabalho estão dados também pelos tratados e naquilo que não reduzam o patamar de garantias asseguradas internamente no próprio país (art. 5ำ, §2ำ, CF/88).

Tais direitos fundamentais do trabalho também constam, evidentemente, da legislação heterônoma estatal, a qual completa o padrão mínimo de civilidade nas relações de poder e de riqueza inerentes à grande maioria do mercado laborativo próprio ao capitalismo (caput do art. $7^{\circ}=\mathrm{CF} / 88$ ) (DELGADO, 2013, p. 61).

É isso que deve ser considerado, ao ser analisar os direitos fundamentais na relação de trabalho: que se está diante de direitos que possibilitam ou, como acima asseverou Delgado (2013), que sejam afirmativos da dignidade da pessoa humana e da valorização do trabalho.

Mascaro Nascimento (2009) averba que os direitos fundamentais, na esfera das relações de trabalho, têm como fundamento a necessidade de garantia de um mínimo ético que deve ser preservado nos ordenamentos jurídicos. Deve-se pensar, destarte, na garantia de direitos indispensáveis para uma sobrevivência digna do trabalhador.

Sarlet (1998) analisa, nesse contexto, o papel do Estado, asseverando que a assistência aos necessitados integra as obrigações essenciais de um Estado Social. Isso inclui, necessariamente, a assistência social aos concidadãos, que, em virtude de sua precária condição física e mental, se encontram limitados nas suas atividades sociais, não apresentando condições de prover a sua própria subsistência.

A comunidade estatal, na visão de Sarlet (1998), deve assegurar-Ihes pelo menos as condições mínimas para uma existência digna e envidar os esforços necessários para integrar estas pessoas na comunidade, fomentando seu acompanhamento e apoio na família ou por terceiros, bem como criando as indispensáveis instituições assistenciais.

\section{PODERES DO EMPREGADOR}

O ordenamento jurídico confere direitos e obrigações às partes do contrato de trabalho, empregado e empregador. Dentre as prerrogativas conferidas ao empresário, destaca-se o poder do empresário, dadas as repercussões jurídicas do seu exercício. 
Godinho Delgado (2013, p. 664) utiliza a expressão 'poder empregatício' para se referir ao "conjunto de prerrogativas com respeito à direção, regulamentação, fiscalização e disciplinamento da economia interna à empresa e correspondente prestação de serviços", poder que se divide em: poder diretivo ou organizativo, poder regulamentar, poder fiscalizatório ou de controle e poder disciplinar.

O poder diretivo ou organizativo confere ao empresário o direito de ordenar seu negócio, definir a atividade econômica, a estrutura jurídica, os cargos existentes, etc.

No poder regulamentar, o empregador traça regras disciplinando o exercício do labor, os objetivos empresariais, as relações com terceiros, podendo estabelecer normas genéricas e abstratas, e criar um regimento/regulamento interno.

O exercício de fiscalização ou controle consiste na emissão de ordens, diretrizes, no acompanhamento dos resultados do trabalho e da observância das normas traçadas.

No poder disciplinar, ao empregador é atribuída a prerrogativa de aplica penalidades/sanções disciplinares ao empregado em razão do descumprimento de obrigações contratuais ou legais relativas ao pacto laboral.

Ressalta-se, com Delgado (1998), a tendência de o Direito do Trabalho criar mecanismos e processos de bilateralização ou multilaterização da dinâmica do exercício do poder no contexto empregatício, em vista da democratização da sociedade política e civil no país.

Na mesma direção, pondera Maria Dolores Santos Fernandes:

Consequentemente, a relação entre o exercício da liberdade do empregador e o complexo de direitos e obrigações derivados do contrato de trabalho adquire uma dimensão bidirecional na medida em que, se a liberdade do empregador interferirá no desenvolvimento da relação de trabalho, também a estrutura bilateral do contrato se projetará sobre aquela liberdade, exigindo a integração de valores sociais em cada momento concreto em que se atue o direito à livre iniciativa da empresa (FERNANDES, 2005, p. $30^{3}$, tradução livre).

Essa mudança paradigmática, no entanto, como qualquer outra, não se faz sem contestações, sem polêmicas. Como bem registra Eduardo Milléo Baracat (2008, p. 11), na obra coletiva 'Controle do Empregado pelo Empregador -

\footnotetext{
3."Consecuentemente, la relación entre el ejercício de la libertad de empresa y el entramad de derechos y obligaciones derivados del contrato de trabajo adquiere una dimensión bidireccional en el sentido de que si bien la libertad de empresa va a incidir en el desaroollo de la relación laboral, también la estrutuctura bilateral del contrato se va a proyectar sobre la libertad de empresa exigiendo la integración de valores sociales en cada momento concreto en que se vaya a actuar el derecho a la libre empresa".
} 
Procedimento Lícitos e llícitos', "a controvérsia decorre dos limites estabelecidos ao exercício do poder de direção, em especial, resultantes dos direitos fundamentais".

\section{OS DIREITOS FUNDAMENTAIS NA RELAÇÃO DE TRABALHO COMO LIMITE AO PODER DO EMPREGADO: CONFLITOS E HARMONIZAÇÃO POSSÍVEL}

Valverde, Guttiérrez e Murcia, em Derecho del Trabajo ${ }^{4}$, ressaltam que os direitos fundamentais, reconhecidos para a pessoa em sua condição como tal e não especificamente em sua condição de participante no processo produtivo, podem ser também exercidos pelos trabalhadores no âmbito das relações de trabalho (NASCIMENTO, 2009, p. 478).

Assim, a inserção do trabalhador na relação produtiva não o destitui de sua condição humana e não afasta ou prejudica o exercício dos direitos fundamentais. A subordinação jurídica não retira os direitos civis ou políticos do trabalhador, os quais devem ser respeitados, inclusive pelo empregador.

Pontue-se, entretanto, que a vida em sociedade é um constante interagir, em que as pessoas estão sujeitas a ver seus direitos em choque com os de seus semelhantes, dando origem a conflitos de interesses. Nem sempre os direitos têm convivência harmônica.

Se os conflitos nascem nas relações sociais existentes entre partes que estão em posição de igualdade, essas relações sociais tendem a se tornarem mais tensas quando existe uma desigualdade fática entre os contratantes, como ocorre nas relações trabalhistas, desigualdade essa reconhecida pelo próprio Direito. Por isso, as relações de trabalho são campo fértil para a ocorrência de conflitos envolvendo direitos fundamentais.

Não se pode olvidar que é o exercício de direitos pelo empregador que gera maiores repercussões jurídico-sociais, pois reflete diretamente na manutenção do vínculo de emprego, na percepção de verbas trabalhistas, enfim, na vida do empregado e de sua família.

Os atos do empregado, por seu turno, de natureza individual e isolada, em regra, têm alcance restrito, sem possibilidade de afetar significativamente os interesses da empresa.

\footnotetext{
${ }^{4}$ Citado por Amauri Mascaro, in Curso de Direito do Trabalho, p. 478.
} 
Dessa forma, conquanto a tutela dos direitos fundamentais não seja privilégio do empregado/trabalhador, é inquestionável que as lesões envolvendo direitos fundamentais ocorrem mais frequentemente em relação à pessoa do empregado/trabalhador, tendo em vista a subordinação deste à direção e disciplina do empregador, além do referencial quantitativo (mais empregados, que empregadores).

Nada impede, no entanto, que esse menoscabo, essa lesão também atinja o patrimônio jurídico do tomador de serviços. Isso porque o contrato de trabalho é sinalagmático, ou seja, há uma dependência recíproca de obrigações e direito.

Fica, portanto, registrada a ressalva. Conquanto a análise de algumas hipóteses fique restrita quase que exclusivamente ao trabalhador, nada impede que o obreiro seja o autor e não a vítima das ofensas.

Na Espanha, a jurisprudência sobre o exercício de direitos fundamentais nas empresas e unidades de trabalho é abundante por duas razões indicadas pelos juristas Valverde, Guttiérrez e Murcia, citados por Nascimento (2009, p. 479): "porque o trabalho é um dos aspectos essenciais da existência humana, e porque as ocasiões de lesão a tais direitos são frequentes na vida profissional".

Os Tribunais do Trabalho têm enfrentado, em todo o mundo, os mais variados casos de conflitos envolvendo os direitos fundamentais do trabalhador em contraposição aos poderes dos empresários.

Podendo ser citados, ilustrativamente, os que seguem, que denotam violência aos direitos fundamentais, por atingir a honra, a dignidade humana, a pessoa do trabalhador, seus valores humanos mais caros, valores merecedores de tutela por todo o ordenamento.

$\mathrm{Na}$ fase pré-contratual, durante o processo de seleção ou escolha do empregado, este se encontra em estado de grande suscetibilidade. A necessidade do emprego, o medo de não ser contratado, a urgência das privações materiais, tudo isso depõe contra uma possível resistência aos atentados contra os direitos fundamentais do trabalhador.

Na legislação brasileira, há expressão disposição legal impedindo-se algumas práticas abusivas na relação laboral (inclusiva na admissão), como dispõe a Lei Federal no 9.029, de 13 de abril de 1995, que obsta a exigência de teste, exame, perícia, laudo, atestado, declaração ou qualquer outro procedimento relativo à esterilização ou a estado de gravidez (artigo $2^{\circ}$ ). 
A vedação é tão significativa e relevante que o ordenamento jurídico brasileiro tipificou tal conduta, sendo esse crime punido com pena de detenção de 01 a 02 anos e multa.

No artigo 1ำ da citada Lei, o legislador destacou sua intolerância a práticas discriminatórias, devendo o empregador pautar seu comportamento em observância ao princípio da igualdade (não-discriminação), sob pena de ofensa ao referido diploma normativo.

Ainda na fase admissional, um assunto para o qual as atenções têm se voltado é a exigência de testes genéticos de candidatos a emprego. Sobre o tema, apresenta-se acertada a ponderação feita por Vicente Pachés (1998), no livro "El derecho del trabajodor al respeto de su intimidad:

É certo que existem riscos genéticos relacionados a determinadas doenças do trabalho e que o empregador tem a obrigação de zelar pela segurança e saúde na empresa, mas esse argumento não é válido para justifica uma utilização arbitrária da análise genética. Será admissível a investigação genética para acompanhar o grau de afetação do trabalhador que esteve exposto a substâncias químicas, se o principal objetivo da investigação é determinar o alcance do dano produzido pela exposição a essas substâncias no trabalho ${ }^{5}$ (Citado por Rafaela Corrêa Leite e Silvia Carine Tramontin Rios, in Controle do Empregado pelo Empregador Procedimentos Lícitos e llícitos, 2008, p. 199, tradução livre).

Por isso, é preciso sempre observar que, como registra Alice Monteiro de Barros (1997, p. 61), na obra Proteção à Intimidade do Empregado, "quaisquer que sejam os métodos adotados, deve-se verificar sua aceitação ética e limitar a avaliação da aptidão profissional do candidato para a execução das funções".

Durante o contrato, pode haver danos a direitos fundamentais, mormente à dignidade do trabalhador, decorrentes de anotação desabonadoras na Carteira de Trabalho e Previdência Social - CTPS, fazendo constar, por exemplo, uma repreensão ou admoestação por equívoco cometido, ou acusação por ato de improbidade, ou mesmo a indicação dos motivos da dispensa.

Valentin Carrion manifestou-se com propriedade a respeito, ponderando que:

Anotações desabonadoras à conduta do empregado são vedadas, pois trariam ao seu titular sérios transtornos para distinguir as inscrições justas e

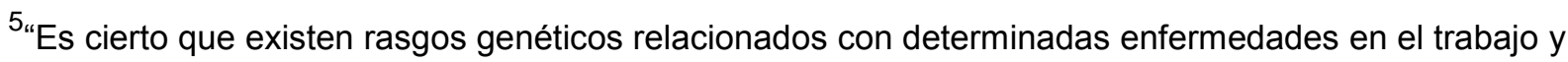
que el empresario tiene la obligación de velar por la seguridad y salud en la empresa, pero elho no es argumento válido para justificar una utilización arbitraria del análisis genético. Será admisible la investigación genética para vigilar el grado de afectación del trabajador que estuvo expuesto a sustâncias químicas tóxicas, al ser la principal pretensión de la investigación determinar el alcance del daño producido como secuencia de la exposición a esas sustâncias en el trabajo".
} 
objetivas das subjetivas ou mesmo das falsas. A redação do art. 31 era expresso na matéria; a revogação do texto de inúmeros artigos, aquele inclusive, não autoriza aquelas anotações, dada a sedimentação do princípio (CARRION, 2002, p. 357).

Os registros em CTPS, pois, devem ser feitos em estrito observância à legislação vigente, sob pena de configurar abuso do direito do empregador, infringindo direitos do empregado.

$\mathrm{Na}$ vigência do pacto laboral, o direito de propriedade tem sido o fundamento utilizado para justificar a realização de revistas íntimas ou de bens, vídeovigilância e monitoramento de e-mails, dando azo às mais acaloradas discussões.

O artigo 373-A da Consolidação das Leis do Trabalho veda expressamente a empregador ou preposto a revista íntima em trabalhadoras, afastando tal essa hipótese e tornando ilícita a conduta do empregador.

Quanto à revista de bens, o magistrado laboral Eduardo Milléo Baracat (2008, p. 09) formula a seguinte indagação, respondendo-a a seguir: "É lícito o ato de revista de bolsas e de sacolas de empregados que o empregador realiza ao final da jornada de trabalho? De acordo com a jurisprudência brasileira, não há uma única resposta correta a esta pergunta".

Acerca do monitoramento de e-mail no local de trabalho, o professor Jorge Luiz Souto Maior destaca que:

\begin{abstract}
A despeito de influir no direito do controle do empregador sobre a atividade do empregado, as Cortes européias vêm dando preferência à preservação da intimidade do empregado, negando a possibilidade do empregador ter acesso às correspondências eletrônicas emitidas e recebidas pelo empregado no local de trabalho, a ponto de negar a possibilidade de dispensa do empregado por tal motivo (vide, neste sentido, decisão proferida pela Corte de Cassação francesa, em 02/10/01, n. W 99-42.942, que se baseou no artigo $8^{\circ}$ da Convenção Européia de Salvaguarda dos Direitos do Homem e das Liberdades Fundamentais) (MAIOR, 2006, p. 199).
\end{abstract}

A matéria, contudo, é árida, porquanto há ferrenhos defensores do direito do empresário a realizar controle das comunicações eletrônicas realizadas pelo empregado. Registre, porém, a tendência a se prestigiar os direitos fundamentais do obreiro em contraponto aos direitos patrimoniais da empresa.

Um dos momentos mais tensos da relação de trabalho ocorre quando de sua extinção. Para o empregado consiste na perda imediata de sua fonte de subsistência, e para o empregador, talvez represente um enorme transtorno na atividade produtiva, pois pode envolver novos custos para seleção e admissão de 
outro empregado, transtornos no desempenho da função por um trabalhador imperito, etc.

Não são raros, pois, os conflitos de interesses no término do contrato laboral. Nessa fase contratual, as despedidas injuriosas/caluniosas, ilegalmente discriminatórias malferem os direitos fundamentais do empregado

O constitucionalista Paulo Bonavides (2004) afirma, com muita propriedade, que o centro medular do Estado social e de todos os direitos de sua ordem jurídica é indubitavelmente o princípio da igualdade. Com efeito, materializa ele a liberdade da herança clássica e com esta compõe um eixo ao redor do qual gira toda a concepção estrutural do Estado democrático contemporâneo.

De acordo com Bonavides, de todos os direitos fundamentais a igualdade é aquele que mais tem subido de importância no Direito Constitucional de nossos dias, sendo, como não poderia deixar de ser, o direito-chave, o direito-guardião do Estado social (idem).

As despedidas fundadas em discriminações injustas têm suscitado intenso debate, mormente aquelas que envolvem portadores de vírus HIV.

A jurisprudência brasileira tem se mostrado sensível à difícil situação do trabalhador soropositivo, entendendo que sua dispensa injusta configura ilegal rompimento contratual por restar evidente a caráter discriminatório.

Dessa forma, ainda que sem reconhecer a existência de garantia de emprego ao mencionado empregado enfermo, a jurisprudência determinada a reintegração ao trabalho, como se observa, e.v., no seguinte julgado, proferido pela mais alta Corte do Judiciário Trabalhista Brasileiro:

Reintegração. Empregado portador do vírus da AIDS - caracterização de despedida arbitrária. Muito embora não haja preceito legal que garanta a estabilidade ao empregado portador da Síndrome da Imuno-deficiência Adquirida, ao magistrado incumbe a tarefa de valer-se dos princípios gerais do Direito, da analogia e dos costumes para solucionar os conflitos ou lides a ele submetidos. A simples e mera alegação de que o ordenamento nacional não assegura ao aidético direito de permanecer no emprego, não é suficiente a amparar uma atitude altamente discriminatória e arbitrária que, sem sombra de dúvida, lesiona de maneira frontal o princípio da isonomia insculpido na Constituição da República Federativa do Brasil. Revista conhecida e provida. (Tribunal Superior do Trabalho, $2^{\mathrm{a}}$ Turma, ERR - 205359/95, Relator Ministro Valdir Righetto, DJ 06.06.1997).

Nem toda discriminação, contudo, fere o direito, mas tão somente aquela arbitrária, ilegítima, sem qualquer razoabilidade. como ressalta a Procuradora do Trabalho Thereza Cristina Gosdal, textualmente: 
Há hipóteses em que o tratamento diferenciado é possível juridicamente, tal qual se verifica, por exemplo, nas medidas de ação afirmativa, como as cotas para portadores de deficiência previstas no art. 93 da Lei n. 8.213/91 e Decreto n. 3.298/99. Hédio da Silva Júnior entende que é possível diferenciar quando houver correlação lógica com a norma de conduta e com os valores constitucionais. Para ele a finalidade da diferenciação deve ser acolhida pelo direito, destinada à promoção real. Já para Luís Roberto Barroso, as diferenciações são "juridicamente toleráveis" quando possuírem fundamento razoável e forem destinadas a um fim legítimo; o elemento discriminatório for relevante e residente nas pessoas que estão sendo diferenciadas; houver proporcionalidade entre o valor objetivado e 0 sacrifício; o meio empregado e o fim buscado for compatível com os valores constitucionais. Como exemplo de desequiparação possível traz o da contratação de guardas penitenciários do sexo feminino para presídio feminino; ou o da contratação de artista negro para comemoração do dia da consciência negra. (GOSDAL, 2003, p. 59).

Como se percebe, inegável e evidente a colisão entre os de direitos fundamentais do trabalhador e o exercício do poder do empregador.

Acentue-se, porém, que os direitos fundamentais devem ser preservados, pois, como bem anota Elisa Rudge:

Em razão da interdependência e indivisibilidade dos direitos humanos, conclui-se que a efetivação desses direitos é indispensável para o exercício de outros direitos e liberdades fundamentais. O direito à vida, por exemplo, exige a eficácia do direito à saúde, e o direito à dignidade reclama o direito à moradia, à educação, à escolha de um trabalho digno e à proteção social em caso de desemprego e outras contingências.

Ademais, importa recordar que o princípio da prevalência dos direitos humanos, disposto no art. 4ํㅡㄹ inciso II, da Constituição da República [CF], é um dos princípios que regem as relações internacionais do Brasil.

Portanto, em obediência a este princípio, bem como aos Direitos Fundamentais consagrados pelo constituinte de 1988, o Estado tem o dever de proporcionar aos indivíduos o pleno exercício dos Direitos Sociais, para que possam viver com dignidade, livres da insegurança causada pelo desemprego e miséria crescentes que assolam o sistema capitalista globalizado. (RAMOS, 2008, p. 14)

No estudo que o juiz federal George Marmelstein Lima (2001) intitulou 'A hierarquia entre princípios e a colisão de normas constitucionais', o magistrado realiza as seguintes ponderações, como forma de nortear o intérprete que está diante de um conflito de tamanha magnitude.

Inicialmente, sabe-se que, do ponto de vista estritamente jurídico (epistemológico), hierarquia entre os princípios. Pode-se, não obstante, cogitar a hipótese de existência de hierarquia axiológica (ou deontológica) entre as normas constitucionais, incluindo-se aí, obviamente, os princípios. No caso de duas regras em conflito (antinomia), aplica-se um dos três critérios apontados pela doutrina (cronológico, hierárquico ou da especialidade), na forma do tudo ou nada (no all or 
nothing): "se se dão os fatos por ela estabelecidos, então ou a regra é válida e, em tal caso, deve-se aceitar a conseqüência que ela fornece; ou a regra é inválida e, em tal caso, não influi sobre a decisão" (LIMA, 2001, p. 11).

No caso de colisão de princípios constitucionais, no entanto, como ressalta o magistrado, porém, não se trata de antinomia, vez que não se pode simplesmente afastar a aplicação de um deles. É o que ocorre nos conflitos envolvendo direitos fundamentais.

As soluções foram desenvolvidas pela doutrina estrangeira e vêm sendo comumente utilizada pelos Tribunais para solucionar casos em que dois princípios entram em rota de colisão. A primeira é a da concordância prática (Hesse); a segunda, a da dimensão de peso ou importância (Dworkin).

A concordância prática pode ser enunciada da seguinte maneira: havendo colisão entre valores constitucionais (normas jurídicas de hierarquia constitucional), o que se deve buscar é a otimização entre os direitos e valores em jogo, no estabelecimento de uma harmonização, que deve resultar numa ordenação proporcional dos direitos fundamentais e/ou valores fundamentais em colisão, ou seja, busca-se o 'melhor equilíbrio possível entre os princípios colidentes';

$\mathrm{Na}$ dimensão de peso e importância, quando se entrecruzam vários princípios, quem há de resolver o conflito deve levar em conta o peso relativo de cada um deles, não se aplicando, tal como ocorre com as regras, o critério do tudo ou nada.

Apresenta-se oportuna a colação de decisão da Relatoria do Exmo. Desembargador Federal do Trabalho Valdir Florindo, do Tribunal Regional do Trabalho da 2ª Região:

DESRESPEITO AOS VALORES DA EMINENTE DIGNIDADE HUMANA. DANO MORAL CONFIGURADO. É salutar que, na vida em sociedade, e na relação de emprego a questão não é diferente, estamos sujeitos a sofrer ou causar danos, sejam eles de ordem moral ou material, e nem por isso estamos imunes à devida reparação, hoje elevada à estatura constitucional. Por seu turno, o trabalho e o lucro são preocupações de todos. Contudo, deve haver a prioridade da pessoa humana sobre o capital, sob pena de se desestimular a promoção humana de todos os que trabalharam e colaboraram para a eficiência do sucesso empresarial. A dignidade humana é um bem juridicamente tutelado, que deve ser preservado e que deve prevalecer em detrimento dos interesses de maus empregadores. $\mathbf{O}$ que é preciso o empregador conciliar, é seu legítimo interesse em defesa do patrimônio, ao lado do indispensável respeito à dignidade do trabalhador. Não se discute que o empregado, ao ser submetido ao poder diretivo do empregador, sofre algumas limitações em seu direito à intimidade. O que é inadmissível, contudo, é que a ação do empregador se amplie de maneira a ferir a dignidade da pessoa humana. Foi exatamente o 
que ocorreu nos autos em epígrafe, onde a reclamada passou a submeter a empregada a situações de constrangimento e evidente discriminação, praticando ilícitos que atingem sua dignidade. As atitudes descritas nos autos revelam notória ofensa à personalidade da reclamante, seus sentimentos, sua honra, enfim, bens que integram a estrutura da personalidade do homem. E, portais razões, há que ser mantida a condenação imposta pela sentença ora guerreada. (6 $6^{\mathrm{a}}$ Turma, Revisora: Desembargadora Ivani Contini Bramante, RO no 00190-2007-025-02-00-5, publicado em 19/09/2008, g.n.).

Dessa forma, não há que simplesmente se defender a extinção ou limitação absoluta do poder empresarial, como forma de garantir os direitos fundamentais na relação laboral. A doutrina e jurisprudência têm apontado, em inúmeras situações, a aplicação do princípio da proporcionalidade como resposta aos desafios que se tem apresentado no cotidiano.

O princípio da proporcionalidade deve ser utilizado pelo operador do direito como meta-princípio, ou seja, como "princípio dos princípios", visando, da melhor forma, preservar os princípios constitucionais em jogo.

Neste sentido, Valkiria Briancini lembra que

As relações de trabalho são formadas por dois sujeitos, de um lado o empregador, que através do poder diretivo tem o poder de dirigir, organizar, fiscalizar a prestação do serviço do empregado; de outro, o empregado, subordinado juridicamente ao empregador. No entanto, o poder diretivo do empregador não é absoluto, mas sim é limitado pela presença dos direitos fundamentais do empregado (e.g. direito fundamental à intimidade, a vida privada, à não-discriminação), que possuem eficácia na esfera das relações de trabalho. Assim, o estudo tem por objeto a colisão de direitos fundamentais nas relações de trabalho entre o poder diretivo do empregador e os direitos fundamentais do empregado.

Nos casos de colisão desses direitos as soluções apresentadas nos casos concretos devem sempre procurar harmonizar as espaços de tensão entre as normas constitucionais a concretizar, procurando manter a unidade da Constituição. Para tanto, nestas situações o intérprete/aplicador do direito emprega o método da ponderação de bens e o princípio da proporcionalidade e de seus subprincípios, como meio de interpretação, aplicação e como forma de sopesamento nas situações de tensão e conflito entre bens constitucionalmente protegidos, que por se tratarem de normas constitucionais não se cogita de hierarquia entre ambas, conforme se constata no estudo tópico realizado em algumas decisões do Tribunal Superior do Trabalho sobre colisão de direitos fundamentais e poder diretivo. (g.n.)

Bonavides (2004, p. 560), com autoridade, declara que "os direitos fundamentais, em rigor, não se interpretam; concretizam-se". Segundo o autor, a metodologia clássica da Velha Hermenêutica de Savigny, de ordinário aplicada à lei e ao Direito Privado, quando empregado para interpretar direitos fundamentais, 
raramente alcança decifrar-Ihes o sentido.

Prossegue o constitucionalista que os métodos tradicionais, a saber, gramatical, lógico, sistemático e histórico, são de certo modo rebeldes a valores, neutros em sua aplicação, e por isso mesmo impotentes e inadequados para interpretar direitos fundamentais. Estes se impregnam de peculiaridades que lhes conferem um caráter específico, demandando técnicas ou meios interpretativos distintos, cuja construção e emprego geraram a Nova Hermenêutica (idem).

Toda essa construção hermenêutica se justifica, de acordo com Bonavides, pela própria estrutura normativa desses direitos fundamentais, que exigem, segundo Kock, "decisões de prioridade" ou primazia, tais como "entre sua pretensão de tutela (Schutzanspruch) e as interferências legislativas ou entre direitos fundamentais conflitantes, isto é, posições constitucionais cuja harmonia deve ser levada a cabo por via do legislador.

A partir daí, leciona Paulo Bonavides (2004), se coloca, obviamente, o recurso ao princípio da proporcionalidade, que também serve de apoio à metologia da Nova Hermenêutica.

Mostra-se, pois, essencial a harmonização entre os direitos fundamentais do trabalhador e o exercício do poder empregatício. Deve haver um esforço contínuo e conjunto, de todos os atores da relação de trabalho, para que se preserve o princípio geral do direito de que 'a ninguém se deve lesar' (neminem laedere).

É merecedora de destaque a consideração realizada por Santos Fernandes, segundo a qual:

\begin{abstract}
Em todo o caso, o contrato há de se converter também em expressão da pessoa do trabalhador; deve servir de instrumento de conciliação e síntese dos interesses das partes, através da incorporação de novos direitos e deveres para ambos. A existência de deveres ativos e positivos do empregador ao lado dos direitos do trabalhador reequilibrará a bilateralidade desaparecida. Chegado a esse ponto, é preciso oferecer um possível reconstrução da estrutura bilateral do contrato, mediante a integração, nessa estrutura, dos interesses do trabalhador. (FERNANDES, 2005, p. $30^{6}$, tradução livre).
\end{abstract}

Faz-se necessário que a dignidade da pessoa humana, seja empregado ou empregador, seja preservada. Como leciona Maurício Godinho (2006), citado por

\footnotetext{
$6 \quad$ "Em todo caso, el contrato ha de convertirse también en expresion de la persona del trabajador; debe servir de instrumento de conciliación y síntesis de los intereses de las partes, a través de la incorporación de nuevos derechos y deberes para ambos. La configuración de deberes activos y positivos del empresario respecto a los derechos del trabajador reequilibrará la bilateralidad desaparecida. Llegados a este punto se hace preciso ofrecer una posible reconstrucción de la estructura bilateral del contrato mediante la integración en ella de esos intereses del trabajador".
} 
Alvarenga (2008), o princípio da dignidade da pessoa humana traduz a idéia de que o valor central das sociedades, do Direito e do Estado contemporâneos é a pessoa humana, em sua singeleza, independentemente de seu status econômico, social ou intelectual. O princípio defende a centralidade da ordem juspolítica e social em torno do ser humano, subordinante dos demais princípios, regras, medidas e condutas práticas.

Rúbia Zanotelli de Alvarenga (2008) consigna, no trabalho 'A tutela dos direitos de personalidade no Direito do Trabalho brasileiro', que o poder empregatício, nas suas quatro dimensões (diretivo ou organizativo, regulamentar, fiscalizatório e disciplinar) encontra limites na dignidade básica da pessoa física do trabalhador e nos Direitos Humanos Sociais do trabalhador que visam a tutelar os Direitos de personalidade do empregado.

A mencionada autora cita, como exemplos de tais direitos, os seguintes: art.

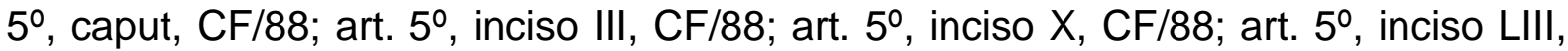
CF/88; art. 5ํ, XII, CF/88; art. 5ำ LIV, CF/88; art. 5ํ, XXIII, CF/88; preâmbulo da CF/88; art. 1ำ, inciso III, CF/88; art. 3ํ, incisos I e IV, CF/88; art. 5o, incisos I, III, X, LIII E LIV, etc. (idem)

Resta válido e juridicamente admitido, como pontua Zanotelli de Alvarenga (2008), o direito obreiro de resistência no âmbito empregatício, que atribui ao empregado a utilização dos mecanismos processuais que visam a eliminar ou atenuar o uso excessivo e abusivo do Poder Empregatício no contexto da relação empregatícia.

Os direitos humanos das diversas dimensões, como ensina Sarlet (1998), gravitam, direta ou indiretamente, em torno dos tradicionais e perenes valores da vida, liberdade, igualdade e fraternidade (solidariedade) tendo, na sua base 0 princípio maior da dignidade humana.

A professora Zanotelli de Alvarenga (2008) ensina que fundar o Direito sobre a dignidade da pessoa humana, por intermédio da aplicação plena desses direitos representa fazer valer o ideário de justiça social tão preconizada pela Carta Magna Brasileira de 1988. 


\section{CONSIDERAÇÕES FINAIS}

Os direitos fundamentais são indissociáveis da ideia de valores éticos e sociais. Assim como estes valores, tais direitos experimentaram, ao longo do tempo, significativa evolução, sendo esta objeto da teoria das gerações ou dimensões dos direitos fundamentais, ressaltando que se cuida de divisão não estanque ou compartimentada desses direitos, porquanto essas gerações se integram e se complementam.

Os direitos fundamentais, por serem direitos atribuídos à pessoa, independentemente de sua condição de trabalhadora, a celebração do contrato laboral não os elimina.

Ao lado dos direitos conferidos ao trabalhador, têm-se as prerrogativas conferidas ao tomador dos serviços, dentre as quais se destaca o poder empregatício, dadas as repercussões jurídicas do seu exercício.

O exercício desses poderes pelo empregador nem sempre têm convivência harmônica com os direitos fundamentais do trabalhador. Se é certo que os conflitos nascem nas relações sociais existentes entre partes que estão em posição de igualdade, essas relações sociais tendem a se tornarem mais tensas quando existe uma desigualdade fática entre os contratantes, como ocorre nas relações trabalhistas, desigualdade essa reconhecida pelo próprio Direito. Por isso, as relações de trabalho são campo fértil para a ocorrência de conflitos envolvendo direitos fundamentais.

Além do desequilíbrio entre as partes do pacto laboral, o trato sucessivo presente no contrato de trabalho também favorece a ocorrência de conflitos entre trabalhador e tomador dos serviços.

Na ocorrência de entrechoque na relação de trabalho, ganha relevo a conduta patronal. É que, ao contrário do agir do trabalhador, é o exercício de direitos pelo empregador que gera maiores repercussões jurídico-sociais, pois reflete diretamente na manutenção do vínculo de emprego, na percepção de verbas trabalhistas, enfim, na vida do empregado, de sua família e da sociedade em geral.

Os atos do empregado, por seu turno, de natureza individual e isolada, em regra, têm alcance restrito, sem possibilidade de afetar significativamente os 
interesses da empresa.

Dessa forma, conquanto a tutela dos direitos fundamentais não seja privilégio do empregado, é inquestionável que as lesões envolvendo direitos fundamentais ocorrem mais frequentemente em relação à pessoa do trabalhador, tendo em vista a subordinação deste à direção e disciplina do empregador, além do referencial quantitativo (mais empregados, que empregadores).

Nada impede, no entanto, que o menoscabo a tais direitos também atinja o patrimônio jurídico do tomador de serviços. Isso porque o contrato de trabalho, como já consignado, é sinalagmático, ou seja, há uma correspondência recíproca de obrigações e direitos.

A doutrina e jurisprudência têm enfrentado, em todo o mundo, os mais variados casos de conflitos envolvendo os direitos fundamentais do trabalhador em contraposição aos poderes dos empresários, cabendo, em algumas hipóteses, o exercício do direito de resistência (jus resitentiae) pelo empregado, em que este se recusa ao cumprimento de ordens abusivas ou ilegais.

Os direitos fundamentais do trabalhador, valores humanos caros e merecedores de tutela por todo o ordenamento jurídico, atuam como diretriz limitante ao exercício dos poderes do empregador. Isso ocorre em todo o período em que trabalhador e empregador, assim considerados, interagem e se relacionam, mesmo antes da celebração do pacto laboral e ainda depois do rompimento contratual.

Embora o trabalhador se encontre em condição de inferioridade fática na celebração e manutenção do pacto laboral, impelido pela exigência de satisfação de necessidades materiais, certo é que o empregado, ao aceitar as condições de trabalho, não se submete a "qualquer condição", pois o "contrato de trabalho parte de um conteúdo mínimo de respeito á dignidade", como bem registra Marlon Murari (2008).

Admitindo não só a ocorrência, mas a inafastabilidade da existência de conflitos entre os direitos fundamentais do trabalhador e o exercício dos poderes do empregador, deve-se ter em mente que a solução para o problema passa, necessariamente, pela ponderação dos valores envolvidos e da dignidade da pessoa humana.

Como se percebe e por todo o exposto, entende-se que, sem olvidar da 
complexidade da tarefa, é essencial e possível a harmonização entre os direitos fundamentais do trabalhador e o exercício do poder empregatício. Deve haver, para isso, um esforço contínuo e conjunto de todos os atores da relação de trabalho, para que se preserve o princípio geral do direito de que 'a ninguém se deve lesar' (neminem laedere), mas, sobretudo, para que sejam prestigiados os direitos fundamentais.

Torna-se possível, destarte, que o contrato de trabalho se apresente como instrumento de convivência justa e pacífica de seus sujeitos, com respeito aos direitos de ambos e restabelecimento da bilateralidade por vezes esquecida.

\section{REFERÊNCIAS}

ALVARENGA, Rúbia Zanotelli de. A tutela dos direitos de personalidade no direito do trabalho brasileiro. Revista Trabalhista Direito e Processo, Anamatra, São Paulo: LTr, n. 26, p. 107-126, 2008.

BARACAT, Eduardo Milléo (coord.). Controle do empregado pelo empregador procedimento lícitos e ilícitos. Curitiba: Juruá, 2008.

BARROS, Alice Monteiro. Proteção à Intimidade do Empregado. São Paulo: LTR, 1997.

BONAVIDES, Paulo. Curso de direito constitucional, 14. ed, São Paulo: Malheiros, 2004.

BRIANCINI, Valkiria. Colisão de direitos fundamentais - aplicação do principio da proporcionalidade nas relações de trabalho. Disponível em: https://repositorio.ucs.br/jspui/bitstream/11338/271/1/Dissertacao\%20Valkiria\%20Bri ancini.pdf. 11 nov. 2007. Acesso em 25 set 2015.

BRITO FILHO, José Cláudio Monteiro de. Trabalho decente: análise jurídica da exploração, trabalho forçado e outras formas de trabalho indigno. 3. ed., São Paulo: LTr, 2013.

CARRION, Valentin. Comentários à consolidação das leis do trabalho. 27. ed. atual. e ampl. por Eduardo Carrion. São Paulo: Saraiva, 2002.

DELGADO, Maurício Godinho. Curso de direito do trabalho. 12. ed., São Paulo: LTr, 2013.

FERNÁNDEZ, Maria Dolores Santos. El contrato de trabajo como límite al poder del empresario. Albacete (Espanha): Bomarzo, 2005. 
GOSDAL, Thereza Cristina. Antecedentes criminais e discriminação no trabalho. Revista LTr, São Paulo, v. 67, n. 7, p. 804-814, 2003.

LIMA, George Marmelstein Lima. A hierarquia entre princípios e a colisão de normas constitucionais. Disponível em: http: //www. http://jus2.uol.com.br/doutrina/texto.asp?id=2625. 01 dez. 2001. Acesso em: 11 set. 2004.

MAIOR, Jorge Luiz Souto. Monitoramento de e-mail no local de trabalho. Revista de Derecho Social LatinoAmerica, Albacete (Espanha): Bomarzo, v. I, p. 199-202, 2006.

MATHIAS, Marcio José Barcellos. Distinção conceitual entre Direitos Humanos, Direitos Fundamentais e Direitos Sociais. Disponível em http://www.direitonet.com.br/artigos/exibir/2791/. 02 ago. 2006. Acesso em: 27 jun. 2009.

NASCIMENTO, Amauri Mascaro. Curso de direito do trabalho. 24. ed. São Paulo: Saraiva, 2009.

RAMOS, Elisa Maria Rudge. Os direitos sociais: direitos humanos e fundamentais. Disponível em http://www.lfg.com.br. 17 dez. 2008. Acesso em: 27 jun. 2009.

SARLET, Ingo Wolfgang. A eficácia dos direitos fundamentais. Porto Alegre: Livraria do Advogado, 1998.

SILVA, Alessandro da. et al. Direitos Humanos: essência do direito do trabalho. São Paulo: LTr, 2007.

- Tribunal Superior do Trabalho (Brasil). Acórdão de decisão que determinou a reintegração de empregado portador do vírus da AIDS despedido arbitrariamente. Recurso de Revista. n..., Segunda Turma. Relator: Ministro valdir Righetto. 06 de junho de 1997. Disponível em http://aplicacao5.tst.jus.br/consultaunificada2/inteiroTeor.do?action=printInteiroTeor\& format=html\&highlight=true\&numeroFormatado=RR\%20-\%20443570016.2002.5.04.0900\&base =acordao\&rowid=AAANGhAAFAAAnLsAAF\&dataPublicaca

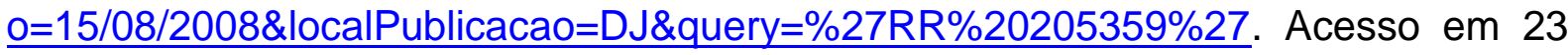
de maio de 2015.

- Tribunal Regional do Trabalho da 2a Região (São Paulo-Brasil). Acórdão de decisão que assegurou a prevalência da pessoa humana sobre 0 capital. Recurso Ordinário no 00190-2007-025-02-00-5, Relator: Valdir Florindo, Revisora: Desembargadora Ivani Contini Bramante, 19 de setembro de 2008. Disponível em http://trt2.jusbrasil.com.br/jurisprudencia/15836212/recurso-ordinario-ro-190200702502005sp-00190-2007-025-02-00-5. Acesso em 23 de maio de 2015. 